\title{
ARTICLE
}

\section{Ethics in the practice of clinical psychology}

\author{
RATHNA ISAAC
}

Clinical psychologist in private practice, 104 Spencer Rd, Frazer town, Bangalore 560005 INDIA email: rathna_i@hotmail.com

\begin{abstract}
The paper presents an overview of ethical issues in clinical psychology. Specifically, it addresses the broad philosophical ideas and views on mental illness on which ethical principles are based, including Greek philosophy and Christianity. It goes on to describe the ethical code of the American Psychological Association as it pertains to general principles, psychological assessment or psychometry, education or training and psychological interventions. The principles of the code and research on the same are discussed with relevance to issues and challenges to ethical practice in India, and suggestions for ethical conduct are made. The paper emphasises the need to consider different viewpoints and take individual responsibility for difficult decisions.
\end{abstract}

"A moral philosophy is not a system for neatly classifying (diagnosing) right and wrong. In the original and more profound sense, moral philosophy refers to a world view that can help therapists to 'hold': to hold the pain of so many who need their strength, to hold their own course through personal difficulties, to hold on to a sense of centre in a world where chaos seems everywhere and growing." (1)

The Oxford English Dictionary defines ethics as "the moral principles that govern a person's behaviour or how an activity is conducted". (2) In the context of clinical psychology, it would imply understanding the moral principles underlying psychological thought and activity. Psychology as a science has always been related to, and embedded in, the political and social attitudes of its time (3). This paper will therefore begin by understanding some of the social, philosophical and religious ideas that have influenced clinical psychology as a field.

\section{Religion, philosophy and ethical behaviour}

Plato and Aristotle were among the earliest western philosophers to ponder and write on moral issues. They emphasised that moral behaviour constitutes choices that are made for the good of both the individual and the society, ensuring individual happiness and the progress of society (4). Christianity, particularly the New Testament, emphasises what are traditionally known as feminine virtues: it considers that all men and women are equal in the eyes of God, that evil can be resisted only by turning to good and that true virtue is true love (4). Thus, service and aid to one's fellow man is held as a high ethical standard. However, as we will see, this was not always applied to the mentally ill.
In modern times, such questions are pondered by psychologists and social scientists as often as they are by religions or philosophers. Anchin summarises the principles on which many current morality theories are based (5):

(a) Absolute standards: certain behaviours or thoughts are right or wrong regardless of circumstance. Religious prescriptions represent absolute standards.

(b) Importance of consequence: if the outcome of the behaviour is beneficial, then the behaviour is ethical.

(c) Based on character: there are certain personal characteristics (kindness or generosity) that are moral and others that are not.

(d) Hedonism: behaviours that lead to the happiness of oneself or others are ethical.

Choices between these competing and complementary theories can be made using William James's notion of pragmatics (5). This approach suggests that "metaphysical disputes should be resolved by examining the practical consequences of all proposed solutions." That is, as each psychological endeavour has its own goal, different moral principles may be applicable to different endeavours (6). For the individual clinical psychologist, this means that, regardless of ethical codes and guidelines, each of us may still have to make ethical decisions on a day to day basis and must be aware of the philosophical position that we consciously or unconsciously hold.

\section{The code of conduct for psychologists}

Human understanding of the source of mental illness has evolved over the centuries. It probably began with primitive notions of demonic possession or divine punishment, exemplified by ideas of witchcraft and exorcism in medieval times. However, the idea of a "psyche" and a psychological treatment is also quite old, with Greek philosophers emphasising the importance of looking within to understand mental disturbance and talking through to deal with it. Scientific scrutiny and emphasis on individual differences during the Renaissance, along placing mental illnesses in the realm of medicine rather than of religion and philosophy, did much to demystify mental disorders at that time (3). The most important change, however, took another three centuries and the humanistic stance of Pinel, Luke and Dix. They put the spotlight on the treatment of the mentally ill and asked 
for more ethical and humanitarian treatment (6). For the first time, professionals seriously considered what they owed their mentally ill clients.

Psychologists' striving for ethical behaviour led to the development of a code of conduct that governs and ensures the rights of client and clinician. The profession gained acceptance as a service provider during World War II when the need was felt for a code of ethics that established clinical psychology as a profession capable of meeting its responsibilities to the public. The atrocities committed by Nazi doctors brought the whole question of medical ethics to the forefront (8). In the US, an ethics committee was formed in 1947 and its recommended code of ethics was circulated as early as 1953. More than 2,000 psychologists contributed substantially to those first guiding principles by sending in case vignettes of ethical dilemmas that they had faced.

The crafters of that first code set the stage for a code of ethics for psychologists to be a continual work in progress (9). The civil rights movement of the 1960s and 1970s kept the code relevant but it was not till 1992 that the code was reworked as enforceable rules of conduct rather than aspirations or values (8). If one looks at the broad ethical principles developed by the American Psychologists Association (APA) in the 1950s and compares it to the 2002 APA Ethical Code, the ideas remain the same (10). Considerations of the good of humanity and society, benefiting clients and not doing them harm, providing a competent service, the importance of the individual, equal and fair treatment, mutual respect, promoting justice, respecting the rights and dignity of other human beings, as well as personal happiness and fulfilment are the important principles.

The Indian Association of Clinical Psychologists has also adopted a code of conduct (11). This is based on the APA code and, though shorter, covers similar areas. This includes:

a. Professional competence and services: The interest of the client is paramount and clinical psychologists should keep abreast of recent developments in the field.

b. Referrals: If proper assessment is not possible this should be communicated to the referral source. If referral to a physician, psychiatrist or other health professional is necessary, this referral should be made.

c. Opinion: Clinical psychologists should take full responsibility for their opinions under all circumstances.

d. Consent: It includes all information about the nature of illness, method of treatment, factors associated with efficacy and risk factors.

e. Client welfare: This is paramount. Therefore clinical psychologists should not take up any case which is not within their competence.

f. Court testimony: This should be based purely on findings and observations and should not include bias and prejudice.

g. Confidentiality: Information should not be disclosed except to a concerned co-professional or an appropriate authority. Test material should not be taken out of the clinic or laboratory except for teaching purposes.
The next section of this paper aims at highlighting certain ethical issues which are relevant to clinical practice in India in the major areas of training, psychometry, and therapy. This is by no means an exhaustive survey of all possible situations or guidelines, but, as the APA itself has said, if a behaviour is not included in this list, it proves neither that it is ethical nor that it is unethical (12).

\section{Education and training in clinical psychology}

The following are important highlights from the APA 2002 code (10):

- Clinical psychologists responsible for education and training programmes seek to ensure that there is a current and accurate description of the programme content, training goals, objectives and requirements that must be met for satisfactory completion of the programme and for certification.

- Appropriate guidelines for evaluation are created and made explicit. Students are evaluated on the basis of their actual performance.

- Teachers and supervisors recognise the power that they have over students or those they supervise and make reasonable efforts to avoid engaging in conduct that is personally harmful to students or those they supervise.

- Specific methods, such as hypnosis and the use of projective tests, are to be taught only to those who have the prerequisite training, legal scope of practice or expertise.

\section{Research and discussion on the code of conduct}

The need for psychological services is rapidly growing in India. Several individuals with varying qualifications and experiences are addressing this need. The clinical psychologist in the institution is merely the tip of the iceberg, with MA level psychologists, counsellors, doctors, special educators, teachers, anganwadi workers and others offering similar services. In India, unlike many other countries, one does not need a licence or proof of adequate supervision in order to offer psychological services. With relatively few clinical psychologists, and a huge need for psychological services, it is inevitable that some therapy and testing will be conducted by unqualified individuals. Further, as the actual roles of the different professions are poorly defined, it is extremely difficult to identify a level of competence or a minimum qualification that is applicable to all. A definition of who is qualified to practice as a clinical psychologist is therefore vital.

The aim of a training programme in clinical psychology is professional competence. This is a complex, multidimensional construct that refers to the professional's overall suitability for the profession in terms of communication, knowledge, technical skills, clinical reasoning, emotions, values, and reflection in psychological practice (13). Psychological fitness in terms of reasoning, emotions and values is much harder to gauge than academic knowledge, though it is equally relevant to the notion of professional competence. Adequate means of evaluating these variables need to be developed and used in 
all clinical psychology courses in the country.

Procidano and others surveyed 137 out of 432 graduate psychology departments in North America in order to understand how issues of competence were addressed (14). They found that competency issues are common, with $89 \%$ of departments reporting at least one student with a deficiency over the past five years and $74 \%$ having policies to deal with such students. As many as $87 \%$ of institutions use screening procedures including interviews $(75 \%)$, recommendation letters (38\%) and personal statements (18\%). Of the "incompetent" trainees, $46 \%$ had limited clinical skills, 34\% had personal or emotional problems and $8 \%$ showed unethical behaviour. When discovered to be deficient, $39 \%$ of students were dismissed, 28\% were referred for psychotherapy, 23\% were counselled into other programmes in the same department, $18 \%$ were counselled out of the institution, $11 \%$ were given a leave of absence, $12 \%$ had increased supervision and $8 \%$ left the field. However, only 41 programmes had formal written policies regarding what to do.

In India, the entrance into clinical psychology courses is based almost purely on marks in the qualifying examination and there do not seem to be policies to deal with students who are academically adequate but not psychologically fit for the profession. It is often left to the individual head of department to make a decision. Based on the findings of Procidano's study the options boil down to helping students cope with their problem or counselling them out of the course (14). Help should include every possible action like academic support special tutoring, mentoring, vocational counselling and psychotherapy. Preferably, there should be a written and public policy on the above.

Much of the clinical training is conducted by supervisors. Smith suggests that supervisors should continually assess whether those they supervise are competent for the job they are assigned. They should avoid delegating work that may harm the client or that the person supervised is not competent to carry out (15). It is also important to clarify the roles of the supervisor and the one being supervised (in writing, if required), outline the nature and structure of supervision and establish a timely and specific process for providing feedback. Both supervisor and those supervised will have to take responsibility for documenting the supervisory discussions and inform the client that the therapist is under training.

\section{Psychometry}

The following are important highlights from the APA 2002 code (10):

- Tests should be constructed using a scientifically valid method. Tests with obsolete or irrelevant norms cannot be interpreted and reported on.

- According to APA guidelines, psychometry is to be performed only in the context of a defined professional relationship.

- The final reports are based on information and techniques that provide appropriate substantiation for the findings. If there are any reservations about the accuracy of the findings, then these are also reported. Clinical psychologists only use those assessments where they are familiar with the reliability, validity, standardisation and outcome studies. Where norms are not directly relevant, this needs to be taken into account.

- Persons who are not qualified for test use and interpretation should not be given access to test material or raw test data.

- Based on the source of referral, there is a clear contract regarding who is going to be informed about the test results. The results are explained to that person (client, legal guardian, school, etc) in a way that is easy for her or him to understand.

- The client has a right to raw test data and to have test results explained in full.

In 1996, the committee on Psychological Tests and Assessments of the APA released an additional statement on the disclosure of test data (16). It highlights the following:

- Test data include an individual's test results, raw test data, records, written or computer generated reports, global scores or individual scaled scores, test protocols, manuals, test items and scoring keys.

- Psychologists or their employing organisations have a formal set of rules to address the retention, review and release of test data. This is communicated to the client prior to testing; if there are limits to confidentiality, the client should be aware of them.

- Informed consent should be obtained from test takers or their legal representatives. The information should include reasons for testing, intended use and range of possible consequences and what testing information will be released and to whom.

- Disclosure of test data to a third party (without consent) is done only when mandated by law or when testing is conducted as part of an admission or screening process. Other valid reasons include:

(a) to provide needed professional services to the client

(b) to obtain professional consultation

(c) to protect the client from harm

(d) to obtain payment for services

- Finally, tests and testing material should be used keeping in mind copyright laws and ownership issues.

\section{Research and discussion on psychometry}

In a country that boasts of few indigenously developed, widely used, psychometrically sound and current instruments, it can be difficult to meet the APA's guidelines on the use of appropriate tests. While tests are quite accessible to clinicians, they are frequently inappropriate. International tests are often not adapted and re-standardised and Indian tests are often standardised and used locally rather than nationally. Many popular adaptations of intelligence and personality tests require updating. Research on this scale requires funding and 
institutional support which may not always be available. The heterogeneity of the Indian population is another stumbling block. A test whose norms have been developed in Bangalore may not be applicable to someone from Patna, and even less so to a villager from Betul. A national level impetus to select five or six core tests, that have proved to be clinically useful through multi-centre trials to standardise them and develop norms, will go a long way in addressing this issue.

Not only do we need good tests, we also need good testers. Testing in the hands of individuals who are not aware of psychological and psychometric theory can do much harm and clients may be left with false and incomplete impressions of their results. This is linked to the problems of competency and qualification discussed earlier.

The other important ethical issue in the area of psychometry is that of revealing test data. Pope, Labachnik and Keith Spiegel, in a 1987 study on ethical beliefs and behaviours of therapists, found that $37 \%$ of therapists felt that it was not unethical to keep raw test data from clients and $30 \%$ of them regularly did so (17). Tubbs and Pomerantz used the same questionnaire in 2001 and discovered that $45 \%$ of therapists frequently did not reveal raw test data to clients (18). Clinicians seem to regularly make decisions about whether to reveal test data or not.

The issue here is about clients' right to information about aspects that are central to their diagnosis and treatment. Not providing full results of psychological tests can be compared to not providing full results of blood tests or MRIs. Clinicians, particularly in India, may also not reveal test results due to the concern that clients will not understand results or their implications. For example, while clinicians are aware that IQ alone does not determine functioning and ultimate success in life, this view is often not shared by lay people. Thus a report of a low IQ can lead to decreased self-esteem or depression that may be unwarranted.

Behnke, commenting on the new code and how it handles conflicts of primary principles, suggests prioritising principles in the following order: first, do no harm; second, protect clients right to self-determination, and third, provide positive help (19). It is important to note that adequately resolving an ethical dilemma entails preserving as much as possible of the value that did not receive priority. To clarify the implications for clinical practice in India, client rights means that if the client wants to know how the test was constructed, what it measures or how it will be scored, this should be revealed even if it compromises scoring and interpretation of test results. Preserving beneficence entails taking steps to limit the distribution of test items or questions and ensuring that individuals are not inappropriately given access to the test. However, if the clinical psychologist deems that the release of test data will cause substantial harm to the client, then protecting the client is more important than their right to self-determination.

In situations where revealing test data might be harmful to the client, the following steps can be taken: (a) Reveal the potential for harm and allow clients to decide if they still want the results. (b) In the case of mentally ill or psychotic clients who may be too compromised to make decisions, discuss the subject with family members and other clinicians. (c) Explicitly stated and clear institutional policy can also form a useful guideline, and should be considered a primary responsibility of all institutions offering clinical psychology services.

\section{Psychological interventions}

Concerns surrounding the ethical practice of psychotherapy are universal. However, clients in India may be less informed about their rights and violations of ethical principles typically go unnoticed and unpunished. Therefore, the responsibility for ethical practice lies even more strongly with the clinician. Ethical behaviour in psychotherapy today emphasises understanding the causes of problems and helping individuals cope better with the environment and make healthy choices. This, we assume, will result in happier individuals and better functioning societies.

The following are important highlights from the APA 2002 code (10):

- Prior to the start of therapy, the nature, anticipated course, therapy timings, fees and confidentiality have to be discussed with the client. Therapists inform their clients if they are still under training and provide details about their supervisor. Clinical psychologists answer all questions as accurately as possible.

- Informed consent is taken. This implies that the client has the capacity to consent, has significant information regarding procedure and has consented freely and without undue influence, and that this consent has been documented. When clients are legally incapable of giving consent, permission is taken from legal guardians. Further, the clinical psychologist explains the procedure in a language that is understandable and considers client preferences and best interests.

- Clinical psychologists do not have sexual relations with clients during therapy and for at least two years after therapy is completed. Clinical psychologists also do not undertake therapy with former sexual partners or have sexual relations with relatives of clients.

- If the services are interrupted by factors such as the therapist's illness, unavailability or relocation, suitable arrangements for continuation of services must be made.

- Therapy is terminated when it becomes clear the client no longer needs the service, is not benefiting from it, or is being harmed by it. Pre-termination counselling, review of therapy and post-termination arrangements should be made.

- Fees are paid with money and not through barter of services. Fee arrangements are made explicit and possible limitations are discussed. Therapy is not to be terminated abruptly due to non-payment of fees.

\section{Research and discussion on psychological interventions}

Miller emphasises the inescapably moral nature of all 
psychotherapeutic endeavours: "What we need is an understanding that the profession of psychology and psychotherapeutic practice is, by its very nature, already the practice of ethics." (20) Whatever the theory or content of therapy, the very definition of "psychological health" has a moral connotation. The major philosophical questions of "what is right or wrong" and "how we are to live our lives" are often translated in the therapy room into a dialogue on individual versus societal rights (5). Different theories may have different perspectives on this. Some theories emphasise that the individual needs to learn how to adjust with society and others (eg feminist) that the individual needs to learn how to negotiate with society.

In the present day, we understand that no one theory of mental illness and human psychology is sufficient. Psychological theory and practice is constantly striving to keep up with the findings of research. This has also thrown up new ethical dilemmas. Anchin identifies three of these: (a) Do we practise those therapies that have been judged efficacious by researchers or those that have been judged effective by clinicians? Which group can be said to have a greater claim to the truth? (b) Is quantitative (positivistic) data closer to the truth or is qualitative (hermeneutic) data closer to the truth? (c) How can we celebrate the diversity of multiple theories but create a unifying paradigm that can guide therapy's evolution? (5). An issue with specific relevance to the Indian context is whether therapies and components of therapies developed in the West are directly applicable to clients in India (21). While certain aspects of human behaviour are universal, there is no doubt that culture has a tremendous impact on how we live our lives and, by extension, the type of solutions and therapies that work for us. Developing, manualising and testing therapies (whether adapted or indigenous) is essential for ethical practice in the field.

The first point covered by the code implies the creation of therapeutic contracts, which includes specifications of goals, techniques, outcome research, the date by which positive results are expected, side effects and a monitoring system by which to track goals and side effects. However, therapy is not such an exact art. Different schools of thought emphasise different processes. Psychoanalysis, for instance, is incompatible with very clear contracts. Szasz argues that leaving the frequency and duration of therapy flexible will increase the control of the client (22). Further, the goals set at the beginning of therapy may be very different from the goals in the middle or towards the end.

Widiger and Rorer highlight the issue of the therapist's responsibility. That is, can we hold the therapist responsible for harmful outcomes or lack of outcomes? (23). In terms of Anchin's ethical approaches, is the therapist's behaviour judged on his/her intentions, on the contract with the client, or on the consequences? (5). Each theoretical model emphasises different causal connections between therapy and change. Some emphasise intrapsychic factors, others systemic or environmental. We still do not have a perfect understanding of what causes therapeutic change and most therapies leave the responsibility at least partially with the client. How, then, can we decide on the ethical responsibility of the therapist - and to what meaningful anchor can they be held accountable?

Widiger and Rorer also discuss client capacity for informed consent (23). On the one hand, clients may not possess the necessary capacities to give informed consent, and clinical psychologists may have to make decisions in order to provide appropriate treatment. This is so not only with psychotic clients, but also those who suffer from depression, anxiety and some personality disorders. On the other hand, questioning a client's capacity can be seen as a paternalistic violation of freedom. But if this paternalism is aimed at empowering them and increasing their autonomy, would it then be ethical? Are we not increasing the options for a substance-dependent individual if we can convince him to take help for substance dependence? Inherent in this issue is the question of the power and authority of the therapist. There is a difference between a friend telling you, "You need help," and a therapist telling you, "You need help," that we cannot ignore. So, are we helping clients or are we trying to mould them into our notion of "psychologically healthy"? Is it possible for clients who are already decompensating and developing a trusting relationship with the therapist to withstand our "suggestions"? And if they did ignore us, would therapy work?

The choice of therapy, the creation of therapeutic contracts, the therapist's responsibility, and informed consent are the primary ethical issues in the practice of psychotherapy. Some of the other relevant issues for which APA has guidelines include (10):

Confidentiality: Psychologists take precautions to maintain the confidentiality and privacy of clients in all forms (oral, written and electronic). Confidentiality may be limited by law or by institutional rules. These limits are to be discussed with the client, family member and/or legal representative at the onset of the contact. Both the limits of confidentiality and the foreseeable uses of the information generated through psychological activities are to be discussed. Fresh discussions are to be held whenever circumstances change.

Disclosure of confidential information: This can be made with the permission of the client, as mandated by law. In the US, disclosure is legally permitted to provide needed professional services, obtain appropriate professional consultations, protect the client and psychologist from harm or obtain payment for services. In order to maintain the privacy of the client, only relevant information is included in reports. Further, confidential information obtained from work is used only for appropriate scientific and professional purposes, and only with persons clearly concerned with such matters.

Personal problems and conflicts: Clinical psychologists should recognise that their personal problems and conflicts can interfere with the effectiveness of their work. In this case they should refrain from that particular activity (therapy, supervision, research) and seek help at the earliest.

Confronting a colleague: The APA suggests that clinical psychologists should actively monitor their colleagues' ethical conduct. This notion is particularly relevant in the Indian context where there are no formal sanctions for unethical 
behaviour. But it could prove difficult as most professionals may prefer to take a loyal and protective stance towards colleagues. Keith-Spiegel and Koocher suggest that immediate intervention could not only solve the problem, but also protect colleagues from the larger system (24). They provide guidelines for confronting an unethical colleague:

1. Identify the relevant ethical principle that has been violated.

2. Assess the strength of evidence that an ethical principle has been violated.

3. Consult with a trusted and experienced colleague who has demonstrated sensitivity to ethical issues.

4. Decide if you wish to confront the colleague directly. Telling others or sending anonymous mails is not usually effective.

5. Schedule a face-to-face meeting in a non-threatening manner.

6. During the meeting, remain calm and self-confident. Avoid a rigidly moralistic demeanour. Allow for alternative explanations.

7. Be constructive and educative rather than judgmental. Take a collaborative stance.

8. Describe your ethical obligation, the relevant ethical principle and the evidence that you have gathered.

9. Give the colleague time to explain and defend himself or herself.

10. If you know the colleague and are already friendly, it may make the job easier, though it could harm an important friendship. If you know the colleague and dislike him or her, examine your motives more carefully. If there is much ill feeling between the two of you, it may be better if someone else does the job.

11. If the colleague becomes abusive or threatening, remain calm. Then either schedule another meeting, or inform him/ her about the steps you plan to take.

In conclusion, having a formal code with behavioural specifics seems to decrease unethical behaviour (18). The primary difference between the Indian and American ethical code is that of accountability. To increase the ethical behaviour of clinical psychologists, we need to develop a mechanism by which they can be held accountable for their behaviour. If we do not take adequate steps soon, this role may be taken over by consumer courts or other groups. Verma notes that as long as the definition, educational qualification, professional status and legal status of the term "clinical psychologist" remains under question, it will be extremely difficult to impose any kind of unified code of conduct (25).

Thus, clinical psychologists need to be aware of their own philosophical position with regard to human beings and mental health, they need to be aware of specific guidelines of behaviour and they need to incorporate this awareness into their everyday practice.

Acknowledgements: The author wishes to acknowledge the support and encouragement of Dr Anisha Shah, Additional Professor, Department of Mental Health and Social Psychology, NIMHANS, in the preparation of this paper for publication.

\section{References}

1. Mahoney MJ. Suffering, philosophy and psychotherapy. Journal of Psychotherapy Integration. 2005 Sep; 15 (3): 337-52.
2. Compact Oxford Dictionary, Thesaurus and Wordpower Guide. Indian Edition. New Delhi: S. Hawker. Oxford University Press; 2005.

3. Brems C, Thevenin DM, Routh DK. The history of clinical psychology. In: Walker CE, editor. Clinical psychology: historical and research foundations. New York: Plenum Press; 1991. p. 3-35.

4. Durant W. The story of philosophy. The lives and opinions of the greater philosophers. New York: John Wiley and Sons; 1933.

5. Anchin JC. Introduction to the special section on philosophy and psychotherapy integration and to the inaugural focus on moral philosophy. Journal of Psychotherapy Integration. 2005 Sep; 15(3): 28498.

6. Day B. Convergent themes across Jamesian and Jungian thought. Journal of Counseling and Development. 1990; 68(4):438-42.

7. Carson RC, Butcher JN. Historical views of abnormal behaviour. In: Abnormal psychology and modern life. 9th ed. New York: HarperCollins Publishers Inc; 1992. Chapter 2..

8. Pettifor JL. Ethics: virtue and politics in the science and practice of psychology. Can Psychol. 1996 Feb; 37(1): 1-12.

9. Smith D. The first code. Monitor on Psychology. American Psychological Association. [serial on the Internet]. 2003 Jan [cited 2009 Mar 15]; 34(1): [about 10 p.]. Available from: http://www.apa.org/monitor/jan03/ firstcode.html

10. No authors listed. Ethical principles of psychologists and code of conduct. Am Psychol. 2002 Dec; 57(12): 1060-73.

11. Indian Association of Clinical Psychologists. Code of Conduct. (Adopted by IACP, circulated to its members). Lucknow: IACP Secretariat; 1993.

12. American Psychological Association. [homepage on the Internet]. Washington, DC, APA; 2002. [cited 2009 Mar 17]. Ethical principles of psychologists and code of conduct. Available from: http://www.apa.org/ ethics/code2002.html

13. Epstein RM Hundert EM. Defining and assessing professional competence. JAMA. 2002 Jan 9; 287(2):226-35.

14. Procidano ME, Busch-Rossnagel NA, Reznikoff $M$, Geisinger KF. Responding to graduate students' professional deficiencies: a national survey. J Clin Psychol. 1995 May; 51(3):426-33.

15. Smith D. Ten ways practitioners can avoid frequent ethical pitfalls. Monitor on Psychology. American Psychological Association. [serial on the Internet]. 2003 Jan [cited 2009 Mar 15];34(1):[about 1 p.]. Available from: http://www.apa.org/monitor/jan03/10ways.html

16. American Psychological Association. [homepage on the Internet]. Washington, DC, Committee on Psychological Tests and Assessment, American Psychological Association. [cited 2009 Mar 17]. Statement on the disclosure of test data; [about 6 pages]. Available from: http://www. apa.org/science/disclosu.html

17. Pope KS, Tabachnick BG, Keith-Spiegel P. Ethics of practice: beliefs and behaviours of psychologists as therapists. Am Psychol. 1987 Nov; 42(11): 993-1006.

18. Tubbs P, Pomerantz AM. Ethical behaviours of psychologists: changes since 1987.J Clin Psychol. 2001; 57(3): 395-9.

19. Behnke S. Release of test data and the new ethics code. Monitor on Psychology. American Psychological Association. [serial on the Internet]. 2004 Nov[cited 2009 Mar 15];35(10):[about 2 p.]. Available from: http:// www.apa.org/monitor/nov04/ethics.html

20. Miller RB. Suffering in psychology:The demoralization of psychotherapy practice. Journal of Psychotherapy Integration. 2005; 15: 299-336.

21. Kapur M. Training observations from the perspective of clinical psychology. In: Kapur M, Shamasundar C, Bhatti RS, editors. Psychotherapy training in India - Proceedings from the National Symposium on Training in Psychotherapy. 2nd ed. Bangalore: NIMHANS Publication; 2001. Chapter 1.

22. Szasz T.The ethics of psychoanalysis: the theory and method of autonomous psychotherapy. New York: Basic Books; 1965.

23. Widiger TA, Rorer LG. The responsible psychotherapist.Am Psychol. 1984 May; 39(5): 503-15.

24. Keith-Spiegel P, Koocher GP. How to confront an unethical colleague. In: Koocher GP, Norcross JC, Hill SS, editors. Psychologists desk reference. New York: Oxford University Press; 1998.

25. Verma SK. The development of standards and the regulation of practice of clinical psychology in India. In: Bellack AS, Hersen M, editors. Comprehensive clinical psychology (Volume II). Amsterdam: Elsevier Science Limited; 1998. 